\title{
Temperature dependence on structure, mechanical and electrical properties of bismuth lanthanum sodium titanate-modified lead zirconate titanate ceramics
}

\author{
Pharatree Jaita $^{\mathrm{a}, \mathrm{b}}$, Parkpoom Jarupoom ${ }^{\mathrm{c}, *}$ \\ a Department of Physics and Materials Science, Faculty of Science, Chiang Mai University, Chiang Mai \\ 50200 Thailand \\ b Science and Technology Research Institute, Chiang Mai University, Chiang Mai 50200 Thailand \\ c Department of Industrial Engineering, Faculty of Engineering, Rajamangala University of Technology \\ Lanna, Chiang Mai 50300 Thailand
}

*Corresponding author, e-mail: noteparkpoom@gmail.com

Received 16 Oct 2019

Accepted 26 Dec 2019

\begin{abstract}
The effects of sintering condition on phase evolution, physical, microstructure and dielectric properties of the PZT-3BLNT ceramics were investigated. The samples were prepared by a conventional mixed oxide method and sintered at the temperatures ranging from $1050-1200^{\circ} \mathrm{C}$ under normal atmosphere for $2 \mathrm{~h}$ dwell time with a heating/cooling rate of $5^{\circ} \mathrm{C} / \mathrm{min}$. X-ray diffraction indicated that the mixed rhombohedral-tetragonal phases were observed at lower sintering temperature of $1050^{\circ} \mathrm{C}$, while the tetragonal phase became dominant at higher sintering temperature $\left(1200^{\circ} \mathrm{C}\right)$. The optimum sintering temperature for preparation of high-density PZT-3BLNT ceramic was found to be $1200^{\circ} \mathrm{C}$. Linear shrinkage and average grain size tended to increase with increasing the sintering temperature. The effects of annealing conditions on mechanical and dielectric properties of the PZT-3BLNT ceramic sintered at $1200^{\circ} \mathrm{C}$ were also studied in this work. It was found that the maximum room temperature dielectric constant $\left(\varepsilon_{r}\right)$ of 1313 and Vickers hardness $\left(H_{\mathrm{V}}\right)$ of $4.38 \mathrm{GPa}$ were achieved for the sample annealed at $950^{\circ} \mathrm{C}$ for $8 \mathrm{~h} \mathrm{dwell} \mathrm{time}$ and this value was $\sim 18-20 \%$ higher than that of the unannealed sample. This result was also well correlated with the maximum relative density observed for this annealing condition.
\end{abstract}

KEYWORDS: sintering temperature, mechanical, microstructure, electrical properties, annealing condition

\section{INTRODUCTION}

Lead zirconate titanate (PZT) has $\mathrm{ABO}_{3}$-type perovskite structure. It has tetragonal and rhombohedral phases with the coexistence of 14 orientation states: 6-tetragonal and 8-rhombehedral. $\mathrm{Pb}\left(\mathrm{Zr}_{0.52} \mathrm{Ti}_{0.48}\right) \mathrm{O}_{3}$ is a composition near the morphotropic phase boundary (MPB) which is essential to allow the strong polarization for piezoelectricity [1]. $\mathrm{Pb}\left(\mathrm{Zr}_{0.52} \mathrm{Ti}_{0.48}\right) \mathrm{O}_{3}$ also possesses high spontaneous polarization, high Curie temperature $\left(T_{\mathrm{c}} \sim 390^{\circ} \mathrm{C}\right)$ and ease of poling [2].

Bismuth sodium titanate (BNT) is known as an attractive lead-free perovskite structure material with good dielectric and piezoelectric performance. It was firstly synthesized by Smolenskii and Agranovskaya [3] in 1959. BNT has a rhombohedral ferroelectric phase at room temperature (RT) $[4,5]$ and transforms to antiferroelectric and paraelectric phases above $220^{\circ} \mathrm{C}$ and $320^{\circ} \mathrm{C}[6,7]$, respectively. It has high Curie temperature $\left(T_{\mathrm{c}} \sim 320^{\circ} \mathrm{C}\right)$ and possesses strong ferroelectric properties with large remanent polarization $\left(P_{\mathrm{r}} \sim 38 \mu \mathrm{C} / \mathrm{cm}^{2}\right)$ at RT $[2,6]$. However, BNT itself was known to have a drawback of high coercive field $\left(E_{\mathrm{c}} \sim 73 \mathrm{kV} / \mathrm{cm}\right)$. $\mathrm{Bi}$ ion is highly volatile at high temperature above $1130^{\circ} \mathrm{C}$ during sintering process, making this material difficult to be poled due to its high conductivity which eventually results in rather low piezoelectricity $[8,9]$. To solve this problem, a modifier using rare-earth elements such as La was suggested by Herabut and Safari [10]. The addition of La to replace $\mathrm{Bi}$ and $\mathrm{Na}$ sites was found to induce lattice distortion and cause changes in microstructure of the ceramic. Adding a small amount of La $(\sim 1.72 \mathrm{wt} \%)$ into BNT led to an improvement of dielectric constant from $240-555$ and the higher Curie temperature of about $345^{\circ} \mathrm{C}$ was observed. Moreover, the piezoelectric coefficient $\left(d_{33}\right)$ value was also improved from $58-91 \mathrm{pC} / \mathrm{N}$.

Both $\mathrm{Pb}\left(\mathrm{Zr}_{0.5} 2 \mathrm{Ti}_{0.48}\right) \mathrm{O}_{3}$ or PZT and 
$\left(\mathrm{Bi}_{0.487} \mathrm{La}_{0.017} \mathrm{Na}_{0.487}\right) \mathrm{TiO}_{3}$ or BLNT ceramics are important materials employed in electromechanical device applications [11]. Thus, the modification of PZT with BLNT is of considerable interest and expects to exhibit better properties than those of the single phase of PZT or BLNT. Since early 2003, BNT-based solid solution with PZT has been studied extensively by Kitagawa et al [12]. He found that BNT could act as a driving force for enhancing the sinterability of PZT ceramic and thus the lower sintering temperature of PZT/BNT ceramics was observed. The influences of sintering conditions on structure and properties of PZT/BNLT system have not previously been studied. Recently, a series of ceramics with formula PZT $/ x$ BNLT $(x=$ $0,0.1,0.5,1.0$, and $3.0 \mathrm{wt} \%$ ) were investigated by Jaita et al [13]. They found that the addition of BNLT improved dielectric properties of the PZT ceramics. The dielectric constant value increased with further increasing BNLT content. The $\mathrm{PZT} / 3.0 \mathrm{wt} \% \mathrm{BNLT}$ (PZT-3BLNT) sample showed maximum dielectric constant $\left(\varepsilon_{r}=1099\right)$ at $1 \mathrm{kHz}$.

However, most works for the modified PZT ceramics are concentrated only on their electrical properties. Furthermore, the effects of sintering and annealing conditions have not been widely investigated. Thus, the effects of sintering conditions on phase, physical properties and microstructure of the PZT-3BLNT ceramic were investigated in this work. The effect of annealing condition on dielectric properties of the PZT-3BLNT ceramic sintered at $1200^{\circ} \mathrm{C}$ was also investigated and discussed. The optimum annealing condition will be given which is expected to provide material with better electrical properties, i.e. dielectric properties.

\section{MATERIALS AND METHODS}

$\mathrm{Pb}\left(\mathrm{Zr}_{0.52} \mathrm{Ti}_{0.48}\right) \mathrm{O}_{3}-3.0 \mathrm{wt} \%\left(\mathrm{Bi}_{0.87} \mathrm{La}_{0.017} \mathrm{Na}_{0.487}\right) \mathrm{TiO}_{3}$ or PZT-3BLNT ceramics were prepared by a solidstate mixed oxide method. Reagent-grade oxide powders of $\mathrm{PbO}$ (99\%, Fluka), $\mathrm{ZrO}_{2}$ (9\%, Riedelde Haën), $\mathrm{TiO}_{2}$ (99\%, Riedel-de Haën), $\mathrm{Bi}_{2} \mathrm{O}_{3}$ (98\%, Fluka), $\mathrm{La}_{2} \mathrm{O}_{3}\left(99 \%\right.$, Cerac) and $\mathrm{Na}_{2} \mathrm{CO}_{3}$ (99.5\%, Carlo Erba) were used as raw materials. The starting powders were weighed based on the stoichiometric ratio, ball-milled for $24 \mathrm{~h}$ in distilled water and then dried using oven drying method. Dried PZT and BLNT powders were calcined separately at the same temperature of $800^{\circ} \mathrm{C}$ for $2 \mathrm{~h}$ with a heating/cooling rate of $5^{\circ} \mathrm{C} / \mathrm{min}$. The calcined PZT and BLNT powders were then weighed, ball-milled again for $24 \mathrm{~h}$ and dried using oven drying method to produce the mixed powders of PZT-3BLNT. A few drops of $5 \mathrm{wt} \%$ PVA were then added as a binder before the obtained powders were pressed into disc-shaped pellets $(10 \mathrm{~mm}$ in diameter) using a 1.5-ton uniaxial press. The green pellets were sintered at $1050-1200^{\circ} \mathrm{C}$ for $2 \mathrm{~h}$ dwell time with a heating/cooling rate of $5^{\circ} \mathrm{C} / \mathrm{min}$ in a covered alumina crucible filled with $\mathrm{PbZrO}_{3}$ powder in order to avoid compositional deviation by $\mathrm{PbO}$ volatilization during sintering process. The firing profile also included $1 \mathrm{~h}$ dwell time at $500^{\circ} \mathrm{C}$ for the binder burnout.

Phase identification was analyzed by X-ray diffractometry (Phillip, X-pert) using $\mathrm{CuK}_{\alpha}$ radiation of $1.5405 \AA$ under $0.02^{\circ}$ sampling interval. Bulk density was measured by Archimedes' method. The theoretical density was calculated based on the theoretical densities of BLNT $\left(5.960 \mathrm{~g} / \mathrm{cm}^{3}\right)$ [10] and PZT $\left(8.006 \mathrm{~g} / \mathrm{cm}^{3}\right)$ [14]. The linear shrinkage value was calculated with an empirical equation: $S_{L}=\left[\left(D_{1}-D_{2}\right) / D_{1}\right] \times 100 ; S_{L}(\%)$ is the linear shrinkage, $D_{1}(\mathrm{~cm})$ is the diameter of the ceramic before sintering, and $D_{2}(\mathrm{~cm})$ is the diameter of the ceramic after sintering. Microstructure was observed by scanning electron microscopy (JEOL, JSM-6335F) and grain size was determined by a mean-linear-intercept method. In accordance with this, the PZT-3BLNT ceramic sintered at $1200^{\circ} \mathrm{C}$ was also annealed at the same temperature of $950^{\circ} \mathrm{C}$ but for different annealing time of $0,8,16$, and $24 \mathrm{~h}$, respectively, before the dielectric characterization was carried out. For the measurement of mechanical properties, the samples were polished to a mirror finish. The well-polished ceramics were then subjected to microhardness tester of Vickers hardness $\left(H_{\mathrm{V}}\right)$ determination. For the electrical measurement, two parallel surfaces of annealed ceramics were polished and painted with silver paste for electrical contacts. Dielectric constant $\left(\varepsilon_{r}\right)$ and dielectric loss $(\tan \delta)$ were measured at room temperature with different frequencies via a LCZ-meter (Hewlett-Packard, 4192A).

\section{RESULTS AND DISCUSSION}

X-ray diffraction patterns of the PZT-3BLNT ceramic sintered at various temperatures are shown in Fig. 1. Based on the graphical analysis, well developed crystallite with the single structure of perovskite had been formed. The BLNT phase or other impurity phases were not observed for all sintering temperatures. At lower sintering temperature $\left(1050^{\circ} \mathrm{C}\right)$, the PZT-3BLNT ceramic consisted of both rhombohedral and tetragonal phases. With increasing the sintering temperature to $1100-1150^{\circ} \mathrm{C}$, the distinct tetrago- 


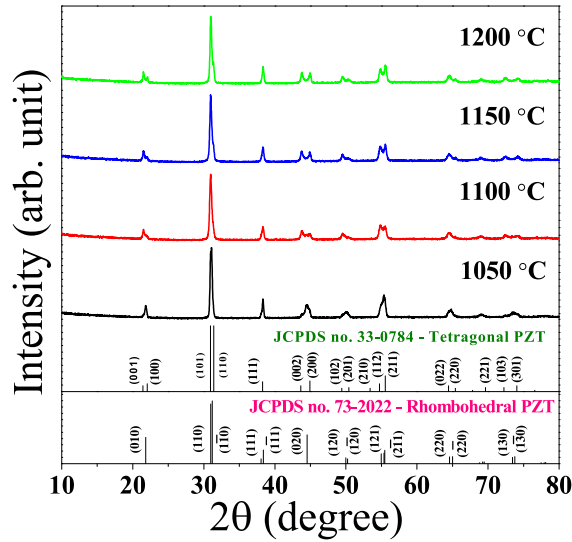

Fig. 1 X-ray diffraction patterns of the PZT-3BLNT ceramics sintered at different temperature of $1050-1200^{\circ} \mathrm{C}$.

Table 1 Physical, microstructure and mechanical properties of the PZT-3BLNT ceramic.

\begin{tabular}{lccrc}
\hline $\begin{array}{l}\text { Sintering } \\
\text { temp. }\left({ }^{\circ} \mathrm{C}\right)\end{array}$ & $\begin{array}{c}\text { Density } \\
\left(\mathrm{g} / \mathrm{cm}^{3}\right)\end{array}$ & $\begin{array}{c}\text { Relative } \\
\text { density }(\%)\end{array}$ & $\begin{array}{c}S_{L} \\
(\%)\end{array}$ & $\begin{array}{c}\text { Grain size } \\
(\mu \mathrm{m})\end{array}$ \\
\hline 1050 & $6.90 \pm 0.08$ & 87.08 & 8.0 & $0.99 \pm 0.09$ \\
1100 & $7.23 \pm 0.03$ & 91.16 & 9.2 & $1.20 \pm 0.10$ \\
1150 & $7.61 \pm 0.01$ & 95.97 & 11.0 & $1.23 \pm 0.10$ \\
1200 & $7.67 \pm 0.03$ & 96.75 & 11.6 & $1.96 \pm 0.20$ \\
\hline
\end{tabular}

nal peak splitting can be seen from the range of $2 \theta=$ $42-47^{\circ}$ corresponding to $(002)_{\mathrm{T}} /(020)_{\mathrm{R}} /(200)_{\mathrm{T}}$ reflections. This suggested that rhombehedral phase was decreased and tetragonal phase became dominant. At high sintering temperature $\left(1200^{\circ} \mathrm{C}\right)$, XRD pattern showed mainly tetragonal structure. However, the presence of tetragonal phase is believed to be the effect of more $\mathrm{PbO}$ evaporation at very high sintering temperature from the covered lead zirconate $\left(\mathrm{PbZrO}_{3}\right)$ powder, as more $\mathrm{PbO}$ loss has strong influence on the shifting of phase composition of the PZT-3BLNT ceramic [15]. Similar observation has been reported in the $\mathrm{Pb}\left(\mathrm{Zr}_{0.52} \mathrm{Ti}_{0.48}\right) \mathrm{O}_{3}+$ $1 \mathrm{wt} \% \mathrm{Nb}_{2} \mathrm{O}_{5}$ systems by Ketsuwan et al [16].

Plots of relative density, linear shrinkage and grain size as a function of sintering temperature of the PZT-3BLNT ceramic are shown in Fig. 2. The related values are also summarized in Table 1 . The results indicated that the minimum values of relative density and linear shrinkage were observed at lower sintering temperature of $1050^{\circ} \mathrm{C}$. This result was well correlated with SEM micrograph as shown in Fig. 3(a) which exhibited quite porous microstructural. As it was expected, with increasing sintering temperature, the relative density and the

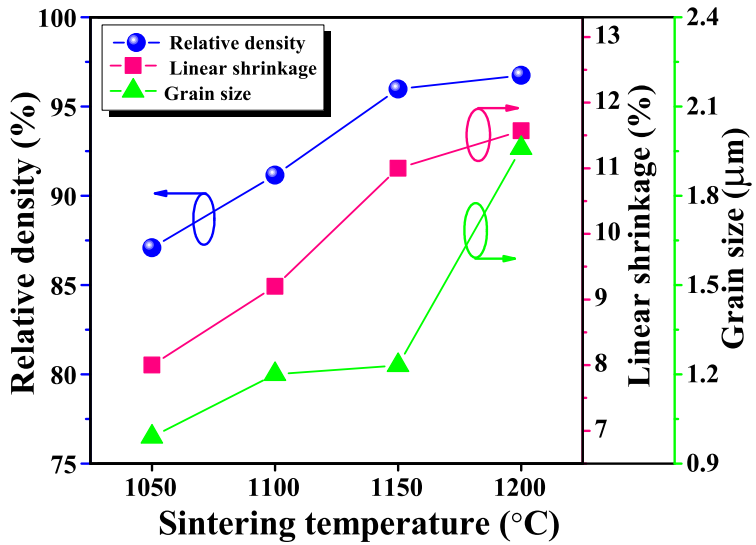

Fig. 2 Plots of relative density, linear shrinkage and grain size values of the PZT-3BLNT ceramics as a function of sintering temperature.

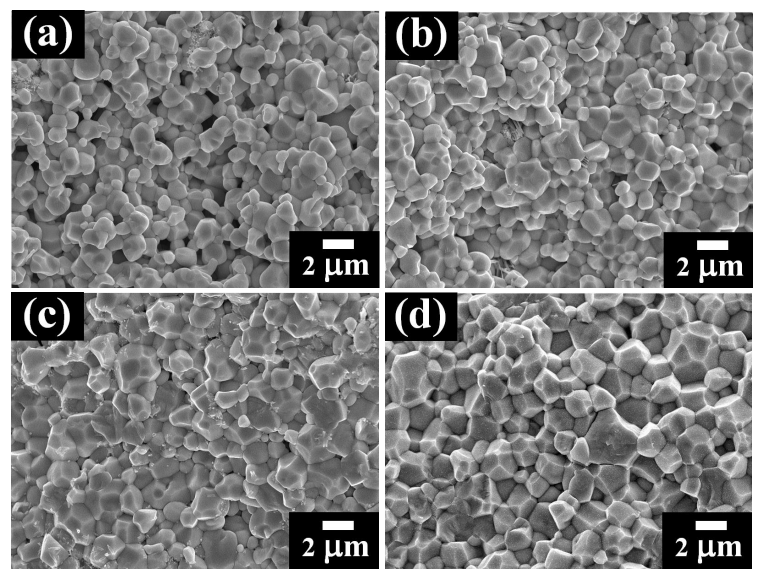

Fig. 3 SEM micrographs of fractured PZT-3BLNT ceramics sintered at (a) $1050^{\circ} \mathrm{C}$, (b) $1100^{\circ} \mathrm{C}$, (c) $1150{ }^{\circ} \mathrm{C}$, and (d) $1200^{\circ} \mathrm{C}$.

linear shrinkage values were increased. The density value was ranked from $87 \%$ of theoretical value for the lowest sintering temperature to $97 \%$ for the highest sintering temperature. The highest relative density of $97 \%$ and linear shrinkage of $12 \%$ were observed in the ceramic sintered at $1200^{\circ} \mathrm{C}$. This suggested that at high sintering temperature was required to improve the shrinkage rate and this effectively enhanced the densification behavior of the PZT-3BLNT ceramic. However, after sintering the pellet-shaped samples at higher temperature over $1200^{\circ} \mathrm{C}$, it was found that some samples started to twist and some samples started to melt. Such high sintering temperature caused the pellets to agglomerate with the covered powder into the hard, irregular-shaped solids. The density value was de- 
Table 2 Physical, microstructure and dielectric properties of the PZT-3BLNT ceramics annealed at $950^{\circ} \mathrm{C}$ with different annealing times.

\begin{tabular}{lccccc}
\hline $\begin{array}{l}\text { Annealing } \\
\text { time }(\mathrm{h})\end{array}$ & $\begin{array}{c}\text { Relative } \\
\text { density }(\%)\end{array}$ & $\begin{array}{c}\text { Grain size } \\
(\mu \mathrm{m})\end{array}$ & $\varepsilon_{r}$ & $\tan \delta$ & $\begin{array}{c}H_{\mathrm{V}} \\
(\mathrm{GPa})\end{array}$ \\
\hline 0 & 96.75 & $1.96 \pm 0.20$ & 1099 & 0.0290 & 3.72 \\
8 & 96.95 & $2.00 \pm 0.13$ & 1313 & 0.0337 & 4.38 \\
16 & 96.60 & $2.04 \pm 0.12$ & 1124 & 0.0265 & 3.81 \\
24 & 96.63 & $2.55 \pm 0.19$ & 999 & 0.0407 & 3.77 \\
\hline
\end{tabular}

creased with increasing temperature in the range of $1250-1300^{\circ} \mathrm{C}$. Earlier reports also observed very similar trend $[17,18]$. Thus, these samples were therefore excluded from further investigation. Since the maximum density and shrinkage values were observed in the ceramic sintered at $1200^{\circ} \mathrm{C}$, these ceramics were chosen for further study of annealing process. The effect of annealing condition on dielectric properties of the PZT-3BLNT ceramic was also studied.

Microstructural development during sintering was investigated by scanning electron microscopy (SEM). Fracture surfaces of the PZT-3BLNT ceramic sintered at various temperatures from $1050-1200^{\circ} \mathrm{C}$ are shown in Fig. 3. The average grain size values are listed in Table 1. It can be seen that the ceramics possessed normal equiaxed grain shape for all sintering temperatures. Grain size value tended to increase with increasing sintering temperature. Similar observations have been reported in other systems [19-22]. This could be a result of higher sintering temperature, effectively inducing more grain growth which occurred by the migration of grain boundaries. Obviously, not all grains could enlarge but the large ones grew at the expense of small ones. Boundary motion is just the shortrange diffusion of atoms from one side of the boundary to the other. Thus, grains increase in size and the total boundary area decreases, yielding a reduction in total energy and this is the driving force for grain growth mechanism governing the observed microstructure and could be explained by the enhancement of diffusion rate with raising the sintering temperature [23].

In this work, the effect of annealing condition on physical, microstructure and dielectric properties of the PZT-3BLNT ceramic sintered at $1200^{\circ} \mathrm{C}$ for $2 \mathrm{~h}$ was also studied. For the microstructural characterization, SEM micrographs with as-sintered surface modes of the PZT-3BLNT ceramics annealed at $950^{\circ} \mathrm{C}$ with different annealing times are shown in Fig. 4(1a-1d). The micrographs clearly showed that annealing time had an influence on the mi- crostructure of the PZT-3BLNT ceramics. Average grain size increased with increasing of the annealing time. The unannealed sample had the average grain size of about $1.96 \pm 0.20 \mu \mathrm{m}$ (Table 2). With increasing annealing time to 8 and $16 \mathrm{~h}$, the average grain size was almost similar $(2.00 \pm 0.13$ to $2.04 \pm 0.12$ ) and was also nearly the same as that of the unannealed sample. However, grain size was apparently increased with further increasing annealing time and showed a maximum value of $2.55 \pm 0.19 \mu \mathrm{m}$ for the sample annealed at $24 \mathrm{~h}$. Based on SEM micrographs with fractured surface modes Fig. 4(2a-2d), it can be seen that the unannealed sample exhibited mainly intergranular fracture grains which indicated its relatively weak grain boundaries. With increasing annealing time to 8 , 16 , and $24 \mathrm{~h}$, the fracture behavior switched from intergranular to transgranular mode, suggesting an increase in grain boundary strength [23].

The effect of annealing time on the mechanical properties in terms of Vickers hardness $\left(H_{\mathrm{V}}\right)$ of the PZT-3BLNT ceramics sintered at $1200^{\circ} \mathrm{C}$ was investigated and shown in Fig. 5 . It can be seen that the $H_{\mathrm{V}}$ value of the unannealed sample was $3.72 \mathrm{GPa}$. The $H_{\mathrm{V}}$ value increased to the maximum value of $4.38 \mathrm{GPa}$ for the sample annealed for $8 \mathrm{~h}$. An increasing of $H_{\mathrm{V}}$ value in the sample annealed for $8 \mathrm{~h}$ is likely due to the densification improvement as shown in Fig. 5 and Table 2.

The observed increases in the dielectric properties induced by annealing time can be attributed mainly to the following factors: (1) the change in the content of the pyrochlore phase, (2) the change in grain size, (3) the change in the density, (4) the grain boundary layer, (5) the release of internal stress, (6) the change in the order degree of B-site ions, and (7) the defect and domain wall motion [24]. In this work, the effect of annealing time on the dielectric properties of the PZT-3BLNT ceramics sintered at $1200^{\circ} \mathrm{C}$ is shown in Fig. 6 . It was found that the dielectric properties of the sample were improved markedly by increasing the annealing time. The maximum room temperature dielectric constant $\left(\varepsilon_{r}\right)$ value of 1313 was achieved for the sample annealed at $950^{\circ} \mathrm{C}$ for $8 \mathrm{~h}$ dwell time and this value was $\sim 20 \%$ higher than that of the unannealed sample. It was believed that thermal annealing can change the distribution of the subregions and the defects, thus eliminating the internal stress. The clamping effect on the motion of microdomain walls was caused by internal stress and defects [24]. As a result, the motion of microdomain walls and polarization reversals 

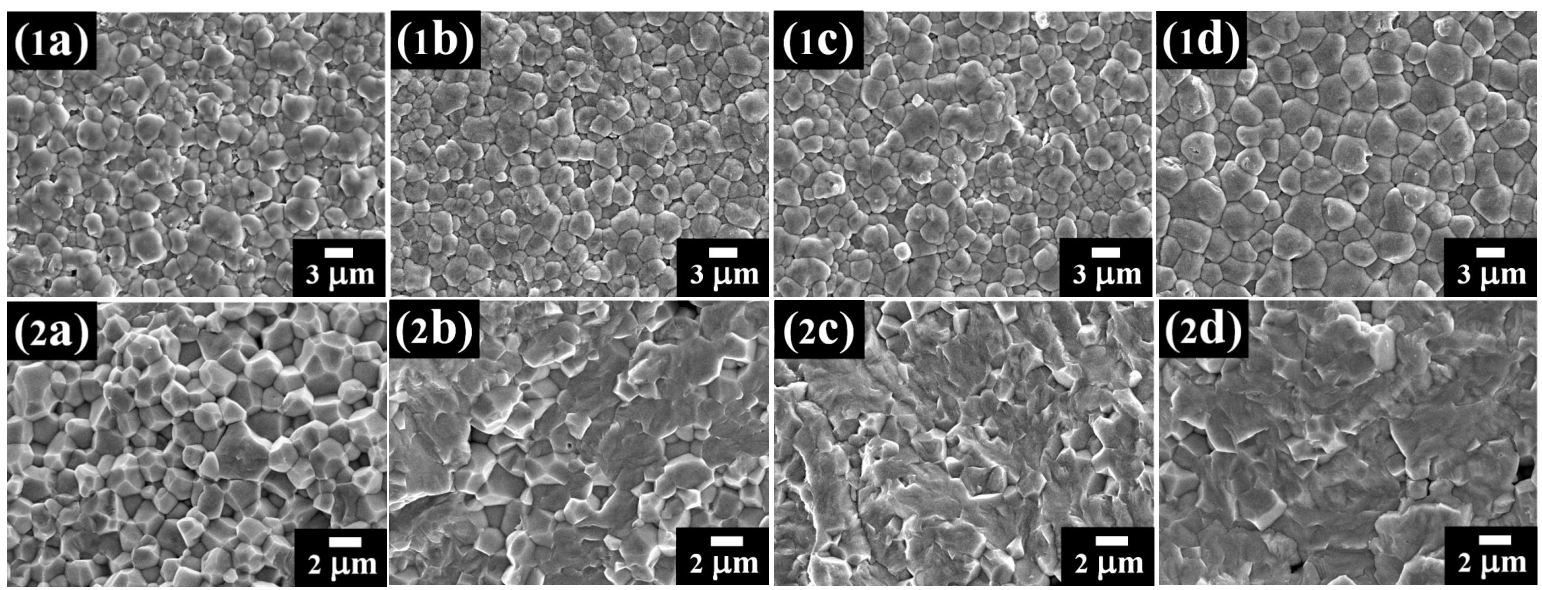

Fig. 4 SEM micrographs of (1) as-sintered surfaces and (2) fractured surfaces of the PZT-3BLNT ceramics sintered at $1200^{\circ} \mathrm{C}$ and then annealed at $950^{\circ} \mathrm{C}$ for different annealing times of (a) $0 \mathrm{~h}$, (b) $8 \mathrm{~h}$, (c) $16 \mathrm{~h}$, and (d) $24 \mathrm{~h}$.

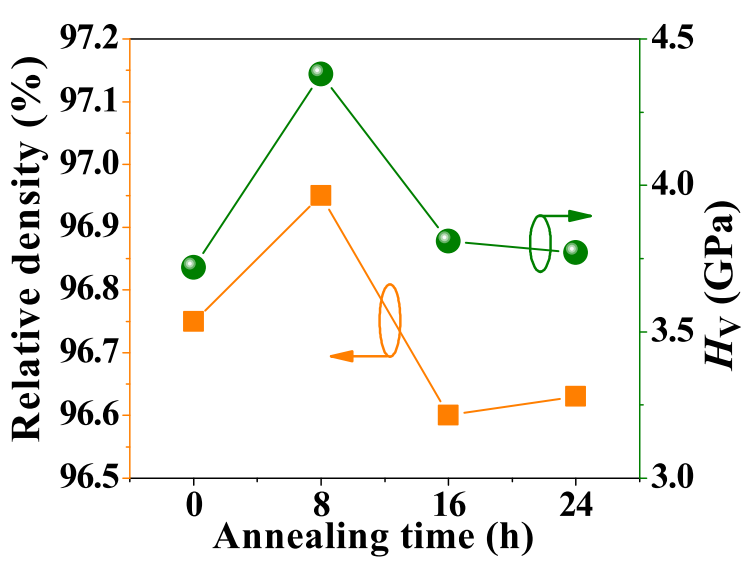

Fig. 5 Plots of relative density and $H_{\mathrm{V}}$ of the PZT3BLNT ceramics (sintered at $1200^{\circ} \mathrm{C}$ ) as a function of the annealing time.

of small polar clusters are enhanced in annealed samples. Consequently, their contributions to dielectric responses will lead to a large increase of dielectric constant value in the annealed sample. This may be the main reason for dielectric property enhancement of the $8 \mathrm{~h}$ annealed sample $[24,25]$. Moreover, this result was also well correlated with the maximum relative density of the PZT-3BLNT ceramics and the average grain size was nearly the same as shown in Fig. 7. Xia et al [24] also observed that the improvement in the electrical properties can be attributed to an extrinsic contribution induced by domain wall motion. After annealing, the pinning effects caused by oxygen vacancies and internal stress on domain wall motion were largely reduced or eliminated. Therefore, a significantly reduced

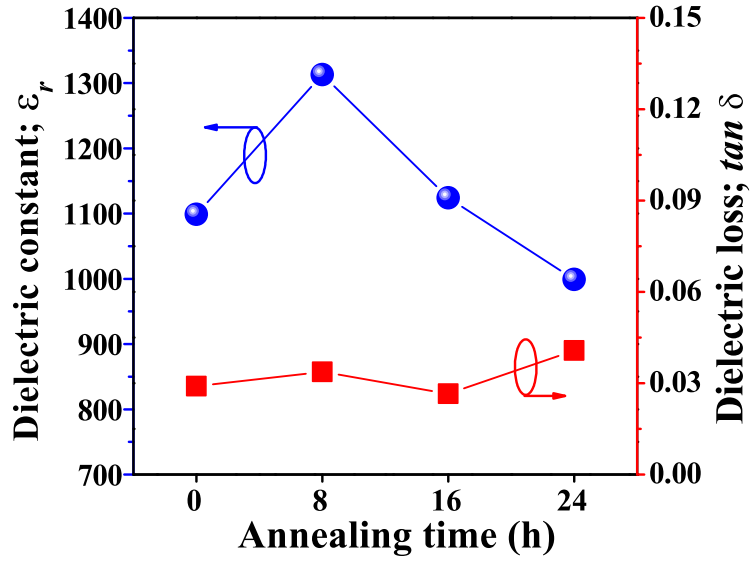

Fig. 6 Plots of dielectric constant $\left(\varepsilon_{r}\right)$ and dielectric loss $\left(\tan \delta\right.$ ) of the PZT-3BLNT ceramics (sintered at $1200^{\circ} \mathrm{C}$ ) as a function of the annealing time.

coercive field, an increased polarization level, and a greatly increased dielectric constant were observed in the PZN-based ferroelectric ceramics. However, the $\varepsilon_{r}$ value dropped to 1124 in the sample annealed for $16 \mathrm{~h}$ and dropped to a minimum value of 999 with further increasing annealing time up to $24 \mathrm{~h}$. In contrast, dielectric loss $(\tan \delta)$ was found to increase with increasing annealing time to $24 \mathrm{~h}$. The decreasing of $\varepsilon_{r}$ for the 16 and $24 \mathrm{~h}$ annealed samples was partly contributed to longer annealing time; the $\mathrm{PbO}$ may highly vaporize during the annealing process, resulting in higher defects in the sample $[24,25]$. Moreover, the decrease in density value was observed for the 16 and $24 \mathrm{~h}$ annealed samples. This was also the reason for the 


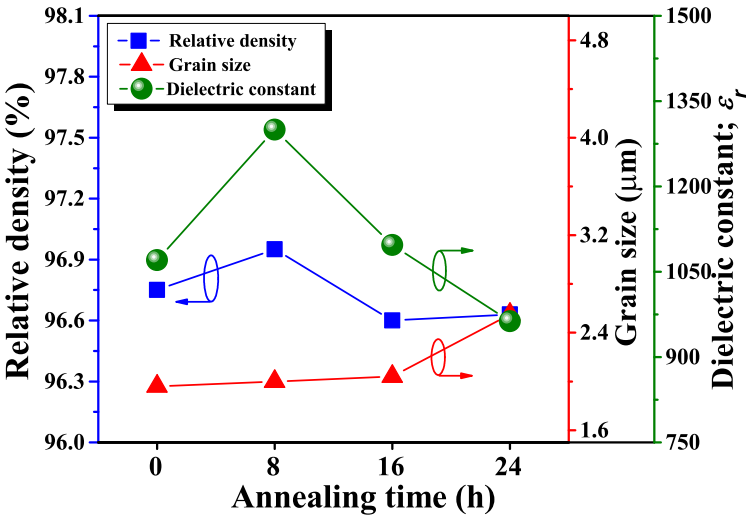

Fig. 7 Plots of relative density, grain size and dielectric constant $\left(\varepsilon_{r}\right)$ of the PZT-3BLNT ceramics (sintered at $1200^{\circ} \mathrm{C}$ ) as a function of the annealing time.

droop of $\varepsilon_{r}$ value in these samples [26]. Rujijanagul et al [25] synthesized the $0.7\left(\mathrm{~Pb}\left(\mathrm{Zr}_{1 / 2} \mathrm{Ti}_{1 / 2}\right) \mathrm{O}_{3}\right)$ $0.3\left(\mathrm{~Pb}\left(\mathrm{Zn}_{1 / 2} \mathrm{Nb}_{2 / 3}\right) \mathrm{O}_{3}\right.$ ceramics by the columbite method. They also found that a longer annealing time produces a loss of $\mathrm{PbO}$ and results in a formation of defects. This made the $32 \mathrm{~h}$ annealed sample have a lower dielectric constant and hardness values. Vittayakorn et al [27] found that the annealing time has an effect on the electrical properties of the PZT-PZN ceramics. The large improvement in the dielectric properties due to annealing time is mainly attributed to the increase in the chemical homogeneity and the extrinsic effect of domain wall motion in ferroelectric ceramics. The maximum room temperature dielectric constant and $H_{\mathrm{V}}$ values were observed in the sample annealed at $950^{\circ} \mathrm{C}$ for $8 \mathrm{~h}$. Therefore, in this work, the optimum annealing time for the enhancement of both mechanical and dielectric behaviors of the PZT-3BLNT ceramics was found to be $8 \mathrm{~h}$ dwell time.

This preliminary study suggested that the sintering temperature played a significant role in phase evolution, density, microstructure and mechanical performance of the PZT-3BLNT ceramic. The results suggested that sintering was nearly completed at $1200^{\circ} \mathrm{C}$ for $2 \mathrm{~h}$ and the annealing temperature of $950^{\circ} \mathrm{C}$ for $8 \mathrm{~h}$ dwell time allowed the process to be completely finished. From this view point, it can be seen that the suitable sintering and annealing conditions could provide the ceramics with excellence and acceptability for both mechanical and dielectric properties.

\section{CONCLUSION}

The PZT-3BLNT ceramics were successfully fabricated by a solid-state mixed oxide and sintering method. With increasing sintering temperature, the crystal structure was changed from mixed rhombohedral-teragonal to mainly tetragonal. The relative density, linear shrinkage and average grain size values tended to increase with increasing the sintering temperature. The optimum sintering temperature for preparing high-density PZT-3BLNT ceramic was found to be $1200^{\circ} \mathrm{C}$. Room temperature dielectric constant and mechanical properties in terms of $H_{\mathrm{V}}$ of the PZT-3BLNT ceramic could be improved by annealing process at the temperature of $950^{\circ} \mathrm{C}$ for $8 \mathrm{~h}$.

Acknowledgements: This work was supported by Department of Industrial Engineering, Faculty of Engineering, Rajamangala University of Technology Lanna and Materials and Manufacturing Research Center, Faculty of Engineering, Rajamangala University of Technology Lanna. Department of Physics and Materials Science, Faculty of Science and Science and Technology Research Institute, Chiang Mai University are also acknowledged.

\section{REFERENCES}

1. Lines ME, Glass AM (1977) Principles and Applications of Ferroelectrics and Related Materials, Oxford Univ Press, Oxford.

2. Jaffe B, Cook WR, Jaffe H (1971) Piezoelectric Ceramics, Academic Press, London.

3. Smolenskii GA, Agranovskaya AI (1959) Dielectric polarization of a number of complex compounds. Sov Phys Solid State 1, 1429-1437.

4. Ivanova VV, Kapyshev AG, Venevtsev YN, Zhdanov GS (1962) X-ray Determination of the symmetry of the ferroelectric compounds $\left(\mathrm{K}_{0.5} \mathrm{Bi}_{0.5}\right) \mathrm{TiO}_{3}$ and $\left(\mathrm{Na}_{0.5} \mathrm{Bi}_{0.5}\right) \mathrm{TiO}_{3}$ and the high temperature phase transitions in $\left(\mathrm{K}_{0.5} \mathrm{Bi}_{0.5}\right) \mathrm{TiO}_{3}$. Bull Acad Sci USSR 26, 358-360.

5. Smolenskii GA, Isupov VA, Agranovskaya AI, Krainik NN (1961) New ferroelectrics of complex composition IV. Sov Phys Solid State 2, 2651-2654.

6. Sakata K, Masuda Y (1974) Ferroelectric and antiferroelectric properties of $\left(\mathrm{Na}_{0.5} \mathrm{Bi}_{0.5}\right) \mathrm{TiO}_{3}-\mathrm{SrTiO}_{3}$ solid solution ceramics. Ferroelectrics 7, 347-349.

7. Pronin LP, Syrnikov PP, Isupov VA, Egorov VM, Zaitseva NV (1980) Peculiarities of phase transitions in sodium-bismuth titanate. Ferroelectrics 25, 395-397.

8. Takenaka T, Maruyama K, Sakata K (1991) $\left(\mathrm{Bi}_{1 / 2} \mathrm{Na}_{1 / 2}\right) \mathrm{TiO}_{3}-\mathrm{BaTiO}_{3}$ system for lead-free piezoelectric ceramics. Jpn $J$ Appl Phys 30, 2236-2239.

9. Takenaka T, Nagata H (2005) Current status and 
prospects of lead-free piezoelectric ceramics. $J$ Eur Ceram Soc 25, 2693-2700.

10. Herabut A, Safari A (1997) Processing and electromechanical properties of $\left(\mathrm{Bi}_{0.5} \mathrm{Na}_{0.5}\right)_{(1-1.5 \mathrm{x})} \mathrm{La}_{\mathrm{x}} \mathrm{TiO}_{3}$ ceramics. $J$ Am Ceram Soc 80, 2954-2958.

11. Haertling GH (1999) Ferroelectric ceramics: history and technology. J Am Ceram Soc 82, 797-818.

12. Kitagawa $\mathrm{K}$, Toyoda $\mathrm{T}$, Yamamoto $\mathrm{T}$ (2003) $\left(\mathrm{Bi}_{1 / 2} \mathrm{Na}_{1 / 2}\right) \mathrm{TiO}_{3}$ Additive effect for improved piezoelectric and mechanical properties in PZT ceramics. J Mater Sci 38, 2241-2245.

13. Jaita P, Watcharapasorn A, Jiansirisomboon S (2010) A role of BNLT compound addition on structure and properties of PZT ceramics. Solid State Sci 12, 1608-1614.

14. Kakegawa K, Mohri J, Takahashi T, Yamamura H, Shirasaki S (1997) A composition fluctuation and properties of $\mathrm{Pb}(\mathrm{Zr}, \mathrm{Ti}) \mathrm{O}_{3}$. Solid State Commun 24, 769-772.

15. Kakegawa K, Matunaga O, Kato T, Sasaki Y (1995) Compositional change and compositional fluctuation in $\mathrm{Pb}(\mathrm{Zr}, \mathrm{Ti}) \mathrm{O}_{3}$ containing excess PbO. J Am Ceram Soc 78, 1071-1075.

16. Ketsuwan P, Ngamjarurojana A, Laosiritaworn Y, Ananta S, Yimnirun R (2007) Effect of sintering temperature on phase formation, dielectric, piezoelectric, and ferroelectric properties of $\mathrm{Nb}$ doped $\mathrm{Pb}\left(\mathrm{Zr}_{0.52} \mathrm{Ti}_{0.48}\right) \mathrm{O}_{3}$ ceramics. Ferroelectrics 358 , $35-41$

17. Chu SY, Chen TY, Tsai TI (2003) Effects of sintering temperature on the dielectric and piezoelectric properties of Nb-doped PZT ceramics and their applications. Integr Ferroelectr 58, 1293-1303.

18. Randll CA, Kim N, Kucera JP, Cao W, Shrout TR (1998) Intrinsic and extrinsic size effects in fine-grained morphotropic-phase-boundary lead zir- conate titanate ceramics. $J$ Am Ceram Soc 81, 677-688.

19. Yimnirun R, Tipakontitikul R, Ananta S (2006) Effect of sintering temperature on densification and dielectric properties of $\mathrm{Pb}\left(\mathrm{Zr}_{0.44} \mathrm{Ti}_{0.56}\right) \mathrm{O}_{3}$ ceramics. Int $J$ Mod Phys B 20, 2415-2424.

20. Hong YS, Park HB, Kim SJ (1998) Preparation of $\mathrm{Pb}\left(\mathrm{Mg}_{1 / 3} \mathrm{Nb}_{2 / 3}\right) \mathrm{O}_{3}$ powder using a citrate-gel derived columbite $\mathrm{MgNb}_{2} \mathrm{O}_{6}$ precursor and its dielectric properties. J Eur Ceram Soc 18, 613-619.

21. Chen TY, Chu SY, Juang YD (2002) Effects of sintering temperature on the dielectric and piezoelectric properties of $\mathrm{Sr}$ additive $\mathrm{Sm}$-modified $\mathrm{PbTiO}_{3}$ ceramics. Sensor Actuat A-Phys 102, 6-10.

22. Chang RC, Chu SY, Lin YF, Hong CS, Kao PC, Lu $\mathrm{CH}$ (2007) The effects of sintering temperature on the properties of $\left(\mathrm{Na}_{0.5} \mathrm{~K}_{0.5}\right) \mathrm{NbO}_{3}-\mathrm{CaTiO}_{3}$ based leadfree ceramics. Sensor Actuat A-Phys 138, 355-360.

23. Callister WD (2003) Materials Science and Engineering: An Introduction, John Wiley \& Sons Inc, New York.

24. Xia F, Yao X (2002) Post sintering annealing induced extrinsic dielectric and piezoelectric responses in lead-zinc-niobate-based ferroelectric ceramics. J Appl Phys 92, 2709-2716.

25. Rujijanagul G, Vittayakorn $\mathrm{N}$, Nabunmee $\mathrm{S}$ (2009) Effect of annealing time on electrical and mechanical properties of $0.7\left(\mathrm{~Pb}\left(\mathrm{Zr}_{1 / 2} \mathrm{Ti}_{1 / 2}\right) \mathrm{O}_{3}\right)$ $0.3\left(\mathrm{~Pb}\left(\mathrm{Zn}_{1 / 2} \mathrm{Nb}_{2 / 3}\right) \mathrm{O}_{3}\right.$ ceramics. Ferroelectrics $\mathbf{3 8 4}$, 68-72.

26. Jarupoom P, Rujijanagul G (2013) Improvement in piezoelectric strain of annealed $\mathrm{Ba}\left(\mathrm{Zr}_{0.07} \mathrm{Ti}_{0.93}\right) \mathrm{O}_{3}$ based ceramics. J Appl Phys 114, ID 027018.

27. Vittayakorn N, Rujijanagul G, Cann DP (2007) The improvement in dielectric and ferroelectric performance of PZT-PZN ceramics by thermal treatment. Curr Appl Phy 7, 582-585. 